\title{
DIAGNOSTIC UTILITY OF AMACR EXPRESSION TO DIFFERENTIATE PROSTATE CARCINOMA FROM BENIGN HYPERPLASIA OF PROSTATE- A HOSPITAL BASED CROSS-SECTIONAL STUDY
}

\author{
Sanat Biswas ${ }^{1}$, Manas Talukdar ${ }^{2}$
}

${ }_{1}^{1}$ Specialist Medical Officer, Department of Pathology, District Hospital Hooghly, Chinsurah, West Bengal, India.

${ }^{2}$ Assistant Professor, Department of Laboratory Medicine, Medical College, Kolkata, West Bengal, India.

\begin{tabular}{l} 
ABSTRACT \\
\hline BACKGROUND \\
Prostatic carcinoma and Nodular Hyperplasia of Prostate (NHP) account for more than $90 \%$ of all prostatic diseases. Also, early \\
symptoms of NHP and prostatic cancers are overlapping. However, the final diagnosis is always based on histopathological \\
examination. Currently Trans-rectal ultrasound-guided core biopsy of prostate is the recommended modality of invasive \\
investigation to rule out cancer in suspected cases. However, the lack of a prostate cancer-specific marker, which can be utilized in \\
conjunction with routine histologic examination, remains a limitation. Few literatures have demonstrated the diagnostic usefulness \\
of alpha-methyl-acyl-CoA-racemase (AMACR) in the detection of prostate cancer. We wanted to find out the sensitivity and \\
specificity of this comparatively new marker and its usefulness in differentiating the benign and malignant lesions of prostate.
\end{tabular}

\section{METHODS}

All the core biopsies sent to the Department of Pathology from July 2016 to August 2018 were utilised in this observational crosssectional study. Only the biopsy reports which could be confirmed by routine H\&E stain were included and reports having suspicious or ambiguous diagnosis by routine H\&E stain were excluded from the study for further assessment by immunohistochemistry (IHC) marker under evaluation. For IHC, primary antibody was 'Rabbit Monoclonal Antibody' to AMACR. The AMACR staining was graded negative, weak or mild (weak non granular cytoplasmic stain), moderate (granular intensity with weak to moderate intensity), and strong (granular staining with strong intensity).

\section{RESULTS}

Out of a total of 106 cases, 68 cases (64.15\%) had confirmed diagnosis of prostatic adenocarcinoma and rest 38 cases (35.85\%) had confirmed diagnosis of benign hyperplasia of prostate by routine H \& E method. Out of the total of 68 cases of prostatic adenocarcinoma, 60 cases (88.23\%) show strong or moderate positive expression of AMACR in neoplastic glands while rest 8 cases $(11.77 \%)$ show weak or negative expression of AMACR. Out of the total of 38 benign cases, only 2 cases (5.26\%) show false positive expression of AMACR. Sensitivity and specificity of this IHC marker came out to be $88.24 \%$ and $94.74 \%$ respectively.

\section{CONCLUSIONS}

The present study proves that AMACR immunostaining has a very high specificity for diagnosis of prostate adenocarcinoma, but its sensitivity is slightly lower. Careful evaluation of morphologic pattern and combination with basal cell marker with AMACR immunostaining might be more useful for exclusion of prostate cancer in needle biopsy specimen.

HOW TO CITE THIS ARTICLE: Biswas S, Talukdar M. Diagnostic utility of AMACR expression to differentiate prostate carcinoma from benign hyperplasia of prostate- a hospital based cross-sectional study. J. Evolution Med. Dent. Sci. 2019;8(18):1435-1438, DOI: $10.14260 /$ jemds/2019/319

\section{BACKGROUND}

Both prostatic carcinoma and nodular hyperplasia of prostate (NHP) are extremely common pathologies of prostate in men with advanced age.[1] Worldwide clinically detected prostate cancer is the third most common malignancy in men with an estimated about 1.2 million new cases in 2018.[2] However, both prostatic cancers and NHP are detected in men aged $>60$ years. Only $1 \%$ of prostate cancers are clinically detected in male aged $<50$ years. [3] Also early symptoms of NHP and prostatic cancers are overlapping. Adenocarcinoma of the prostate may be clinically suspected based on elevated serum PSA and/or abnormal digital rectal examination.

'Financial or Other Competing Interest': None.

Submission 15-03-2019, Peer Review 17-04-2019,

Acceptance 26-04-2019, Published 06-05-2019.

Corresponding Author:

Dr. Manas Talukdar,

10/1, Girish Ghosh Street,

Kolkata-700108, West Bengal,

India.

E-mail: talukdarmanas09@gmail.com

DOI: $10.14260 /$ jemds $/ 2019 / 319$

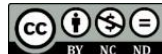

Serum PSA has been used in prostatic carcinoma screening and for diagnostic, therapeutic and prognostic purposes. ${ }^{[4]}$ However the final diagnosis is always based on histopathological examination. Currently TRUS is the first modality of choice to image and biopsy in case of suspected prostatic pathology.[5,6] Current standard of care is to obtain systematic prostate 18 gauge core biopsies guided by transrectal ultrasound from suspected areas as identified by digital rectal examination and imaging. ${ }^{[5,7]}$ Toi et al reviewed 7426 biopsies and found that the presence of a sonographic lesion significantly increased the likelihood of cancer detection. ${ }^{[8]}$

But sometimes making a definitive diagnosis of limited prostate cancer can be diagnostically highly challenging. Previous studies showed that basal cell markers such as $34 \beta E 12$ and p63 have been useful in the evaluation of small foci of atypical glands.[9-11] However, few benign atypical lesions such as atypical adenomatous hyperplasia (AAH), high-grade prostatic intraepithelial neoplasia (HGPIN), and post atrophic hyperplasia (PAH) may show discontinuous or patchy staining, causing diagnostic dilemmas.[12-14] Hence, the lack of a prostate cancer-specific marker, which can be 
utilized in conjunction with routine histologic examination, remains a limitation.

Alpha-methyl-acyl-CoA-racemase (AMACR), an enzyme involved in beta-oxidation of branched chain fatty acids and their derivatives is up regulated in prostatic carcinomas. A monoclonal antibody to AMACR, known as P504S has been produced and is currently available commercially for use on routine formalin-fixed, paraffin embedded tissue sections.[15] Previous studies from different countries have shown the diagnostic usefulness of AMACR in the detection of prostate cancer and its expression pattern in putative precursor lesions such as HGPIN and AAH.[16-20] In present study, we tried to find out the sensitivity and specificity of this comparatively new marker and its usefulness to differentiate the benign and malignant lesions of prostate.

\section{METHODS}

After obtaining approval from Institutional Ethics Committee, this hospital based observational cross-sectional study was carried out in the Department of Pathology, R. G. Kar Medical College, Kolkata. The core biopsies were taken from the lesions with the help of transrectal ultrasound and additional cores from suspected lesion as identified by digital rectal examination in the Department of Urology, R. G. Kar Medical College, Kolkata. All the core biopsies sent to the Department of Pathology from July 2016 to August 2018 were utilised in the study.

Routine paraffin embedded sections were prepared and stained with Haematoxylin \& Eosin stain (H\&E stain.) The slides thus prepared then were examined under light Microscope to detect the pathological lesion. Only the biopsy reports which could be confirmed by routine H\&E stain were included and reports having suspicious or ambiguous diagnosis by routine H\&E stain were excluded from the study for further assessment by the IHC marker under evaluation. The sample size was calculated from the formula: $n=$ $\left[\left\{(\mathrm{Z} \alpha / 2)^{2} \mathrm{X} \mathrm{p} \mathrm{X}(1-\mathrm{p})\right\} \div \mathrm{d}^{2}\right]$ where $\mathrm{n}$ is the sample size, $\mathrm{Z} \alpha / 2$ is a constant of value 1.96 considering $95 \%$ confidence interval, $\mathrm{p}$ is the estimated proportion of malignant cases is taken as $66 \%$, based on study of Jiang $\mathrm{Z}$ et al [15] and $\mathrm{d}$ is the precision which was taken as 9 .

For IHC, tissue sections of 3-micron thickness were cut and fixed with poly-L-lysine coated slides. Following paraffin removal and rehydration, antigen retrieval was done by Pressure cooker methods. Then sections were incubated with commercially available Primary Antibody [Rabbit Monoclonal Antibody to AMACR, P504s (13H4), Cell Marque] for 1 hour. Sections later were washed and treated with diaminobenzidine and hydrogen peroxide (DAB chromogen solution) for 5 minutes. Sections were counterstained with haematoxylin. Epithelial cells of colonic carcinoma were taken as positive control for AMACR staining. The AMACR staining was graded negative, weak or mild (Weak non granular cytoplasmic stain), moderate (Granular intensity with weak to moderate intensity), strong (Granular staining with strong intensity).

The data to compare age groups were statistically analysed by unpaired t-test whereas false positive and false negative percentage along with sensitivity, specificity and positive predictive value of the IHC test concerned were calculated by GraphPad Quick Calcs software.

\begin{tabular}{|c|c|c|}
\hline Disease Group & Mean Age ( \pm SD) & p Value \\
\cline { 1 - 2 } $\begin{array}{c}\text { Benign hyperplasia of } \\
\text { prostate }(\mathrm{N}=38)\end{array}$ & $62.79( \pm 8.67)$ & \\
\cline { 1 - 2 } Adeno-CA of prostate $(\mathrm{N}=68)$ & $65.12( \pm 8.87)$ & \\
\cline { 1 - 1 } & \multicolumn{2}{|c|}{$\begin{array}{c}\text { Group } \\
\text { Table 1. Comparison of Age in Benign and Malignant }\end{array}$} \\
\hline
\end{tabular}

\begin{tabular}{|c|c|c|}
\hline $\begin{array}{c}\text { Confirmed } \\
\text { Histopathological } \\
\text { Diagnosis by H\&E } \\
\text { Method }\end{array}$ & $\begin{array}{c}\text { Number of Cases } \\
\text { Showing AMACR } \\
\text { Moderate or } \\
\text { Strong Positive } \\
\text { Expression }\end{array}$ & $\begin{array}{c}\text { Number of Cases } \\
\text { Showing AMACR } \\
\text { Weak or Negative } \\
\text { Expression }\end{array}$ \\
\hline $\begin{array}{c}\text { Adenocarcinoma } \\
\text { prostate (n=68) }\end{array}$ & $60(88.23 \%)$ & $08(11.77 \%)$ \\
\hline $\begin{array}{c}\text { Nodular hyperplasia } \\
\text { of prostate (n=38) }\end{array}$ & $02(5.26 \%)$ & $36(94.74 \%)$ \\
\hline
\end{tabular}

Table 2. Comparison of AMACR Expression in Cases of Adenocarcinoma Prostate and Nodular Hyperplasia Prostate

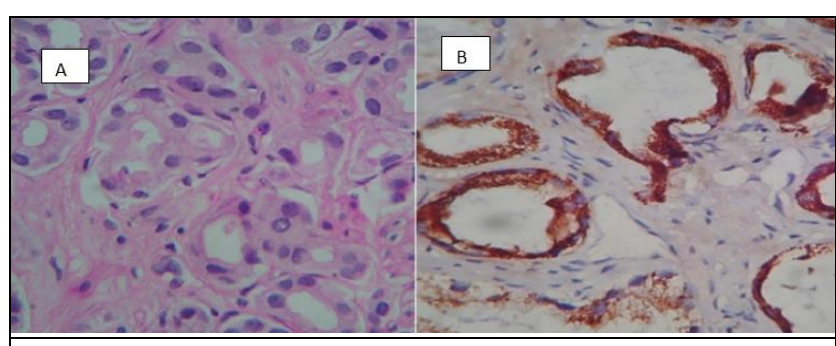

Figure 1. (A) Adenocarcinoma of Prostate (H\& E, 400X); (B) Strongly Positive AMACR Expression in The Luminal Cells of Adenocarcinoma Prostate (400X)

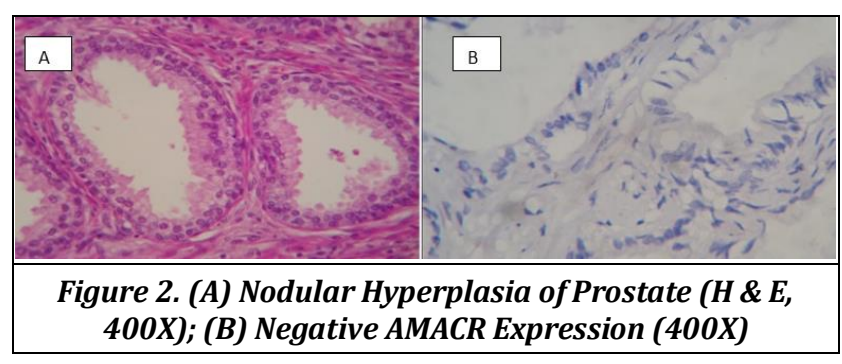

\section{RESULTS}

Total 106 cases were included in the present study as per inclusion and exclusion criteria. Out of total 106 cases, 68 cases $(64.15 \%)$ had confirmed diagnosis of prostatic adenocarcinoma and rest 38 cases (35.85\%) had confirmed diagnosis of benign hyperplasia of prostate by routine $\mathrm{H} \& \mathrm{E}$ method. Regarding the age group, the mean age group for benign cases were $62.79( \pm 8.67)$ and for malignant cases $65.12( \pm 8.87)$. The difference of mean age is not statistically significant to differentiate benign and malignant group ( $p$ value $=0.194$; Table 1 ).

Regarding IHC, out of total 68 cases of prostatic adenocarcinoma, 60 cases (88.23\%) show strong or moderate positive expression of AMACR in neoplastic glands (Figure 1) while rest 8 cases $(11.77 \%)$ cases show weak or negative expression of AMACR. Out of total 38 benign cases, only 2 cases $(5.26 \%)$ show false positive expression of AMACR (Table-2) and rest 36 cases show weak or negative expression (Figure 2). On statistical analysis, sensitivity and 
specificity of this IHC marker came out to be $88.24 \%$ and 94.74\% respectively. Thus, AMACR staining is a highly specific positive IHC marker for diagnosis of prostatic adenocarcinoma with Positive Predictive Value of as high as $96.77 \%$

\section{DISCUSSION}

The prostatic carcinomas are typically a disease of men older than 50 years of age.[1] In present study, the mean age for adenocarcinoma of prostate was $65.12( \pm 8.87)$. It is concordant with previously reported various studies [21-23]. Hariharan $\mathrm{K}$ observed that peak age group for incidence of prostate cancer was above 65 years. [21] The study of Huang et al revealed that patients younger than 50 years accounted for only $0.55 \%$ of all patients with prostate cancer.[22] In United States, Prostate carcinoma is the $3^{\text {rd }}$ leading cause of death due to cancer in males in age group of 60 to 79 years.[23] Regarding BHP, it is also a disease of men of older age group with mean age group above 50 years as revealed by previous studies.[24,25] In present study, the mean age for BHP is 62.79 $( \pm 8.67)$ and statistically it is not helpful to differentiate with prostate cancer (Table- 1 ).

The diagnosis of prostate carcinoma in Tru-Cut biopsy specimens is mainly based on a constellation of morphologic features and sometimes can be highly challenging if only a small localized focus suggestive of carcinoma is noted in the specimen.[26] Basal cell markers such as $34 \beta E 12$ and p63, a nuclear protein, can be used as an adjunct to morphologic examination in these types of challenging settings.[9-11] However, these markers also have drawbacks like many benign atypical entities such as AAH, PAH, and HGPIN show sparse or discontinuous staining that may raise diagnostic dilemmas.[12-14] In this context AMACR has generated tremendous interest and is emerging as an excellent tissue biomarker for prostate cancer. Jiang et al[15] demonstrated P504S, a monoclonal antibody to AMACR, to be a reliable and highly sensitive and specific marker for prostate cancer that could be used in formalin-fixed, paraffin-embedded tissue sections using routine immunohistochemical procedures. They demonstrated that P504S expressed strong, cytoplasmic, granular staining in $100 \%$ of the unequivocal prostate cancer cases, with diffuse staining in $75 \%$ of cases examined, regardless of Gleason scores.[15] Jiang et al[20] later performed another study where they reported slightly lower sensitivity (94.5\%) of P504S in the detection of small foci of prostate cancer in needle biopsy specimens. In this study, none of the 69 benign prostate cases or benign glands adjacent to prostate cancer expressed P504S.[20] Rubin et al[17] using a wide variety of specimens, also found increased activity of AMACR at the transcript and protein levels in prostate carcinoma cases. In present study, AMACR staining showed $88.24 \%$ sensitivity and $94.74 \%$ specificity to diagnose prostate cancer. Thus, the present study also demonstrated high specificity and sensitivity of this marker like previous studies though the percentage varies in different published literature. Beach $\mathrm{R}$ et al[18] also demonstrated that a negative P504S immunostain could not automatically rule out prostate cancer, as $18 \%$ of cases were negative in their study. In present study also $11.77 \%$ cases of prostate carcinoma showed negative AMACR staining. Kunju et al[27] also concluded that P504S, though a useful marker, had a relatively low sensitivity for the detection of prostate cancer, particularly when only a limited focus was present in the needle biopsy specimen. They demonstrated that prostate cancer could have been missed in $10 \%$ of needle biopsy specimens containing unequivocal prostate cancer and 29\% of specimens showing atypical small glandular proliferations suggestive of prostate cancer if P504S had been used alone. This limitation may be due to heterogeneous expression of P504S seen within prostate cancer. Magi-Galuzzi et al. in the year 2003 reported the sensitivity of AMACR staining may vary in specimen in different pathology laboratories, possibly related to differences in fixation and tissue processing.[28] $\mathrm{K}$ Kumaresan et al. in the year 2010 showed that immunohistochemistry with HMWCK and AMACR on the 50 suspicious cases along with controls, AMACR had a sensitivity of $92 \%$ and a specificity of $100 \%$ whereas HMWCK had a sensitivity of $100 \%$ and a specificity of $84 \%$.[29] From the above study it appears that use of two IHC markers could yield better results with regard to sensitivity and specificity. Kunju et al opined that improved sensitivity also was accompanied by relatively higher staining in benign glands. This observation also indicates the fact that P504S expression should be correlated with histo-morphologic evaluation and used in conjunction with traditional basal cell markers to improve its efficacy in diagnosing prostate cancer.

\section{CONCLUSIONS}

The present study proves that immunohistochemistry for AMACR expression has a very high specificity and positive predictive value for diagnosis of prostate adenocarcinoma, but its sensitivity is slightly lower. Hence, careful evaluation of morphologic pattern and combination with basal cell marker with AMACR immunostaining might be more useful for exclusion of prostate cancer in needle biopsy specimen.

\section{REFERENCES}

[1] Epstein JI, Loton TL. The lower urinary tract and male genital system. In: Kumar V, Abbas AK, Fausto N, et al, eds. Robbins and Cotran pathologic basis of disesae. $9^{\text {th }}$ edn. Philadelphia: Saunders Elsevier 2016.

[2] Ferlay J, Ervik M, Lam F, et al. Cancer Today (powered by GLOBOCAN 2018)IARC Cancer Base No. 15. 2018. https://gco.iarc.fr/today/data/factsheets/populations /900-world-fact-sheets.pdf.

[3] Humphrey PA, Amin MB, Berney DM, et al. Acinar adenocarcinoma. In: Moch H, Humphrey PA, Ulbright $\mathrm{TM}$, et al, eds. WHO classification of tumours of the urinary, system and male genital organs. $4^{\text {th }}$ edn. Lyon: International Agency for Research on Cancer 2016.

[4] Antenor JA, Han M, Roehl KA, et al. Relationship between initial prostate specific antigen level and subsequent prostate cancer detection in a longitudinal screening study. J Urol 2004;172(1):90-3.

[5] Harvey CJ, Pilcher J, Richenberg J, et al. Applications of transrectal ultrasound in prostate cancer. Br J Radiol 2012;85 Spec No 1:S3-17.

[6] Heidenreich A, Bastian PJ, Bellmunt J, et al. EAU guidelines on prostate cancer. Part 1: screening, diagnosis, and local treatment with curative intentupdate 2013. Eur Urol 2014;65(1):124-37.

[7] Hameed 0, Humphrey PA. Immunohistochemistry in diagnostic surgical pathology of the prostate. Semin Diagn Pathol 2005;22(1):88-104. 
[8] Toi A, Neill MG, Lockwood GA, et al. The continuing importance of transrectal ultrasound identification of prostatic lesions. J Urol 2007;177(2):516-20.

[9] O'Malley FP, Grignon DJ, Shum DT. Usefulness of immunoperoxidase staining with high-molecularweight cytokeratin in the differential diagnosis of small-acinar lesions of the prostate gland. Virchows Arch A Pathol Anat Histopathol 1990;417(3):191-6.

[10] Shah RB, Zhou M, LeBlanc M, et al. Comparison of the basal cell-specific markers, 34betaE12 and p63, in the diagnosis of prostate cancer. Am J Surg Pathol 2002;26(9):1161-8.

[11] Wojno KJ, Epstein JI. The utility of basal cell-specific anti-cytokeratin antibody (34 beta E12) in the diagnosis of prostate cancer. A review of 228 cases. Am J Surg Pathol 1995;19(3):251-60.

[12] Bostwick DG, Srigley J, Grignon D, et al. Atypical adenomatous hyperplasia of the prostate: morphologic criteria for its distinction from welldifferentiated carcinoma. Hum Pathol 1993;24(8):819-32.

[13] Bostwick DG, Algaba F, Amin MB, et al. Consensus statement on terminology: recommendation to use atypical adenomatous hyperplasia in place of adenosis of the prostate. Hum Pathol 1994;25(8):840.

[14] Gaudin PB, Reuter VE. Benign mimics of prostatic adenocarcinoma on needle biopsy. Anat Pathol 1997;2:111-34.

[15] Jiang Z, Woda BA, Rock KL, et al. P504S: a new molecular marker for the detection of prostate carcinoma. Am J Surg Pathol 2001;25(11):1397-404.

[16] Luo J, Zha S, Gage WR, et al. Alpha-methylacyl-CoA racemase: a new molecular marker for prostate cancer. Cancer Res 2002;62(8):2220-6.

[17] Rubin MA, Zhou M, Dhanasekaran SM, et al. Alphamethylacyl coenzyme A racemase as a tissue biomarker for prostate cancer. JAMA 2002;287(13):1662-70.

[18] Beach R, Gown AM, De Peralta-Venturina MN, et al. P504S immunohistochemical detection in 405 prostatic specimens including 376 18-gauge needle biopsies. Am J Surg Pathol 2002;26(12):1588-96.
[19] Yang XJ, Wu CL, Woda BA, et al. Expression of alphamethylacyl-CoA racemase (P504S) in atypical adenomatous hyperplasia of the prostate. Am J Surg Pathol 2002;26(7):921-5.

[20] Jiang Z, Wu CL, Woda BA, et al. P504S/alphamethylacyl-CoA racemase: a useful marker for diagnosis of small foci of prostatic carcinoma on needle biopsy. Am J Surg Pathol 2002;26(9):1169-74.

[21] Hariharan K, Padmanabha V. Demography and disease characteristics of prostate cancer in India. Indian J Urol 2016;32(2):103-8.

[22] Huang TH, Kuo JY, Huang YH, et al. Prostate cancer in young adults seventeen-year clinical experience of a single center. J Chin Med Assoc 2017;80(1):39-43.

[23] Siegel R, Ma J, Zou Z, et al. Cancer statistics 2014. CA Cancer J Clin 2014;64(1):9-29.

[24] Lee YJ, Lee JW, Park J, et al. Nationwide incidence and treatment pattern of benign prostatic hyperplasia in Korea. Investig Clin Urol 2016;57(6):424-30.

[25] Yeboah ED. Prevalence of benign prostatic hyperplasia and prostate cancer in Africans and Africans in the Diaspora. J West Afr Coll Surg 2016;6(4):1-30.

[26] Epstein JI. Diagnostic criteria of limited adenocarcinoma of the prostate on needle biopsy. Hum Pathol 1995;26(2):223-9.

[27] Kunju LP, Rubin MA, Chinnaiyan AM, et al. Diagnostic usefulness of monoclonal antibody P504S in the workup of atypical prostatic glandular proliferations. Am J Clin Pathol 2003;120(5):737-45.

[28] Magi-Galluzzi C, Luo J, Isaacs WB, et al. Alphamethylacyl-CoA racemase: a variably sensitive immunohistochemical marker for the diagnosis of small prostate cancer foci on needle biopsy. Am J Surg Pathol 2003;27(8):1128-33.

[29] Kumaresan K, Kakkar N, Verma A, et al. Diagnostic utility of $\alpha$-methylacyl CoA racemase (P504S) \& HMWCK in morphologically difficult prostate cancer. Diagn Pathol 2010;5:83. 